\title{
Survival and success of implants in a private periodontal practice: a 10 year retrospective study
}

\author{
Amelie Bäumer ${ }^{1,2^{*}}$, Shirin Toekan ${ }^{3}$, Daniel Saure ${ }^{4}$ and Gerd Körner ${ }^{2}$
}

\begin{abstract}
Background: To assess long-term results of implants (XiVE/Frialit-2 Synchro) in a private periodontal practice according to survival and success rates (biological and technical complications) and to detect possible influencing factors, retrospectively.

Methods: Implant placement of at least one implant took place 10 years \pm 6 months before clinical and radiographic re-examination. Incidence of implant loss as main and incidence of mucositis/ peri-implantitis as secondary outcome were detected. Also, patient-related and implant-related influencing factors were determined by regression analyses.

Results: 100 patients (59.0\% female) with 242 implants were included into analysis. Survival rate was 94.0\% (XiVE: 97.7\%; Frialit-2-Synchro: 66.7\%). Mucositis was found in $77.6 \%$ of all patients, moderate/severe peri-implantitis in 16.3\%. In logistic regression analyses statistically significant influencing factors for implant loss was implant type $(p<0.001)$, for mucositis a wider implant diameter $(p=0.0438)$ and a high modified Plaque Index $(p=0.0253)$, for peri-implantits number of implants per patient $(p=0.0075)$ and a wider implant diameter $(p=0.0079)$. Technical complications were found in 47 implants (19.4\%).

Conclusions: XiVE implants showed a high survival rate over a 10-year follow-up, on the other hand Frialit-2 Synchro implants had worse survival rates. Success rates regarding biological complications are in line with other implant systems.
\end{abstract}

Keywords: Implants, Survival, Mucositis, Peri-implantitis, XiVE

\section{Background}

Long-term data regarding survival and success rates over periods of 10 years or more are available for different implant systems [1-4]. However, just one long-term study over 10 years is published for the implant system XiVE S Cellplus (Fa. Dentsply Sirona Implants,

\footnotetext{
* Correspondence: ab@paroplant.com; amelie.baeumer-koenig@med.uniheidelberg.de

'Section of Periodontology, Department of Conservative Dentistry, Clinic for Oral, Dental and Maxillofacial Diseases, University Hospital Heidelberg, Im Neuenheimer Feld 400, 69120 Heidelberg, Germany

2Private Practice, Niedernstrasse 16,33602 Bielefeld, Germany

Full list of author information is available at the end of the article
}

Mannheim, Germany) with an implant survival rate of 83.0\% [5], another one over a shorter observation period of 7.5 years [6]. For the implant system Frialit-2-Synchro (Fa. Dentsply Sirona Implants, Mannheim, Germany) similar survival rates of $87 \%$ over a period of 4.5 years can be found [7] as well as stable bone changes over 10 years [8]. However, long-term data on these implant systems are still rare.

Also, the incidence of peri-implant mucositis and periimplantitis is still not clear because of different definitions in the literature $[9,10]$. A review by Derks \& Tomasi (2015) stated the incidence of peri-implant

C C The Author(s). 2020 Open Access This article is licensed under a Creative Commons Attribution 4.0 International License, which permits use, sharing, adaptation, distribution and reproduction in any medium or format, as long as you give appropriate credit to the original author(s) and the source, provide a link to the Creative Commons licence, and indicate if changes were made. The images or other third party material in this article are included in the article's Creative Commons licence, unless indicated otherwise in a credit line to the material. If material is not included in the article's Creative Commons licence and your intended use is not permitted by statutory regulation or exceeds the permitted use, you will need to obtain permission directly from the copyright holder. To view a copy of this licence, visit http://creativecommons.org/licenses/by/4.0/ The Creative Commons Public Domain Dedication waiver (http://creativecommons.org/publicdomain/zero/1.0/) applies to the data made available in this article, unless otherwise stated in a credit line to the data. 
mucositis with a wide range of 19-65\% (weighted mean prevalence of $43 \%$ ) and of peri-implantitis with $1-47 \%$ (22\%, respectively). Furthermore, they found that extent and severity of the disease were rarely reported.

Several influencing factors for peri-implant mucositis and peri-implantitis are also described. For the development of peri-implant mucositis the factors plaque accumulation, residual cement excess or smoking seems to have an impact [11]. For peri-implantitis risk factors such as smoking [12-14], a history of periodontitis [4, $15,16]$, plaque accumulation [17], non-compliance to recall [18], residual excess cement [19] or number of implants [15] could be detected. But there might be more influencing factors for these diseases than assessed so far, e.g. the width of keratinized gingiva.

Due to the few long-term data for the implant systems XiVE and Frialit-2 Synchro, the aim of this study was to assess long-term data of biological (survival rates, mucositits, periimplantitis) and technical complications of these implants placed in patients in a private periodontal practice. It was supposed that these implants show similar results like others do in a periodontally compromised but treated clientel. Furthermore, potential influencing factors for implant loss, peri-implant mucositits and peri-implantitis should be determined.

\section{Methods}

The study was performed in accordance with the Declaration of Helsinki 1975, as revised in 2008, and was approved by the Institutional Review Board for Human Studies of the Medical Faculty of Heidelberg University (Application\# S-210/2013). All patients were informed about possible risks and benefits as well as the procedures of the study and all gave written informed consent at the re-examination.

The presented study has a retrospective design combined with a prospective long-term re-examination.

\section{Study population}

All patients were treated in a private practice from 2003 to 2006 by implant placement of at least one XIVE S Cellplus or Frialit-2-Synchro Implant (Fa. Dentsply Sirona Implants, Mannheim, Germany) by one surgeon (GK). All patients received at least one session of individual hygiene before implants were placed. When a periodontitis was detected a complete active periodontal therapy (APT) was conducted before. Smokers received implant treatment if the maximum daily dose did not exceed 10 cigarettes/day. After implant placement all patients were incorporated into a recall program. This contained re-instruction and re-motivation to an effective individual plaque control, professional mechanical plaque removal and once a year obtaining a dental and periodontal status. Sites exhibiting periodontal pocket depth (PPD) of $4 \mathrm{~mm}$ plus bleeding on probing (BOP) and sites with $\mathrm{PPD} \geq 5 \mathrm{~mm}$ were scaled subgingivally $[20,21]$.

All treated patients were invited to a re-examination 10 years \pm 6 months after implant placement until 100 patients could be included when fulfilling the following inclusion criteria:

- Available radiograph at implant placement (+ 3 months) and/or time of inserting the implantsupported prosthetic (orthopantomogramm or $\mathrm{x}$ ray)

- Available attachment level or panoramic radiograph/ complete $\mathrm{x}$-ray status to classify patient's periodontal diagnosis at baseline

$-\geq 18$ years at re-examination

- Non-pregnant or breastfeeding

- Partially edentulous dentition

- At least one XIVE S Cellplus or Frialit-2-Synchro Implant (all patients with Biomet Implants were excluded due to the low number of these patients $(n=$ 3)).

\section{Surgical and prosthetic procedures}

Data on time for healing after extraction was recorded. The surgical procedure included bone augmentation, if necessary. One week after implant insertion the sutures were removed. In cases without bone augmentation or only minor augmentations loading of the implants was conduced about 3 months after implantation, in cases of major augmentation (e.g. external sinus lift, block augmentation) loading time was about 4-5 months. Fixed supra-structures were mostly cemented with a temporary cement (TempBond $\left.{ }^{\circ}\right)$. In case of decementation, Rely $\mathrm{X}^{\bullet}$ was taken as cement. Just few supra-structures were screwed.

\section{Clinical examination}

Complete clinical re-examinations were performed by one independent and calibrated examiner $(\mathrm{AB})$ from November 2013 to May 2016. They included:

- Medical history

- Familial history regarding periodontitis

- Self-reported comprehensive smoking history, whereby patients were categorized as current, former and non-smokers [22] as well as measurement of carbon monoxid via Compact Smokerlyzer ${ }^{\circ}$ (Fa. Bedfont Scientific Ltd., UK)

- Questionnaire on smoking at baseline (current, former and non-smoker)

- Self-reported educational status and classification into three groups: low (primary school), moderate (intermediate secondary education, apprenticeship) or high (upper secondary education) 
- Questionnaire on complications with implantsupported restorations during the last 10 years: none, major complications (implant fracture, loss of supraconstruction), medium complications (abutmend fracture, veener or framework fracture, phonetic complications), minor complications (abutment/ screw loosening, de-bonding, loss of retention, minor chipping)

- Dental status

- Periodontal status: probing pocket depth (PPD) and vertical attachment levels (CAL-V) to the nearest $1 \mathrm{~mm}$ using a manual periodontal probe (PCPUNC 15; HuFriedy, Chicago, IL, USA) at six sites per tooth/implant, bleeding on probing (BOP) and suppuration on probing (SUP), assessment of furcation involvement [23] and mobility

- Modified Gingival Index (mGI) and modified plaque index (mPII) at all implants ([24])

- Width of keratinized mucosa at six sites per implant in $\mathrm{mm}$ (in the maxilla just three sites due to the masticatory palatal mucosa)

- Digital x-ray (periapical radiographs) of all implants

- Evaluation of the implant-supported restoration at each implant regarding technical complications

\section{Patients' charts}

Retrospective evaluation of patients' charts was accomplished by two examiners (ST, $\mathrm{AB}$ ) independently and included:

- Baseline periodontal diagnosis according to the classification from 1999 [25] retrospectively on the basis of the baseline examinations (dental and periodontal status, radiographic examination)

- Periodontal treatment before implant placement (none, non-surgical, surgical)

- Compliance to the recall program: a frequency of at least two visits per year was recommended. When extending the recall interval once over 100\% (i.e. returning after 13 months for recall) the patient was non-compliant.

- Recurrence of periodontal disease: at re-examination percentage of sites with PPD $\geq 5 \mathrm{~mm}$ was detected. A recurrence of active periodontal disease was considered, if more than $30 \%$ of a patient's teeth showed PPD of $\geq 5 \mathrm{~mm}$ at re-examination [21]

- Type, length and diameter of implants

- Time of implant placement

- Augmentation of soft/hard tissues and time of augmentation

- Form of implant healing (submerged or nonsubmerged)

\section{Radiographic analysis and assessment of bone loss}

Bone loss was calculated by comparing baseline radiographs with radiographs at re-examination. The following distances were measured at the mesial and distal aspect of the implant by using a computer program (VixWin Platinum Version 1.4, Fa. Gendex, Hatfiels, USA) under standardized conditions in a darkened room by two examiner (ST, AB):

- Implant shoulder to limbus alveolaris or if present to bony defect

- Implant length ('apical-coronal' length).

The implant length reported by the manufacturer was used for the calibration of the distances. The largest value was taken as the extent of bone loss. As proposed a measurement error of $0.5 \mathrm{~mm}$ was included [26]).

\section{Definition of biological complications}

According to Derks et al. (2016) mucositis was defined as presence of $\mathrm{BOP} /$ suppuration but no detectable bone loss. Peri-implantitis was defined as presence of bone loss of $>0.5 \mathrm{~mm}$ with/without BOP/SUP and a moderate/severe peri-implantitis was stated when bone loss reached $>2.0 \mathrm{~mm}$. Implant survival was given when the implant was not lost during the last 10 years.

\section{Statistical analysis}

All data were entered into two separate data files (Excel version 2003, Microsoft Corporation, Redmond, WA, USA) by two investigators (ST, AB). These data were compared thereafter. All differing entries were doublechecked by means of comparison with the original patients' charts.

Primary outcome was survival of implants, secondary outcome implant success (no mucositis, no periimplantitis, no technical failures).

Descriptive statistical analysis with rates for qualitative characteristics and with mean, standard deviation, median, minimum and maximum for quantitative outcome was performed using R 3.2.2 ( $\mathrm{R}$ Foundation for Statistical Computing, Vienna, Austria, www.r-project.com). This software was also used for logistic regressions with either implant loss or mucositis or peri-implantitis or severe peri-implantitis as dependent variable on both patient and implant level. As independent factors predefined variables were included without variable selection and the significance level was chosen to be 0.05 , which was not adjusted for multiple testing, also because of the descriptive nature of this study. A $\chi^{2}$-test was conducted to test for a difference between smokers and non-smokers according to smokerlyzer. Spearman correlation was used to correlate the width of keratinized 
210 patients

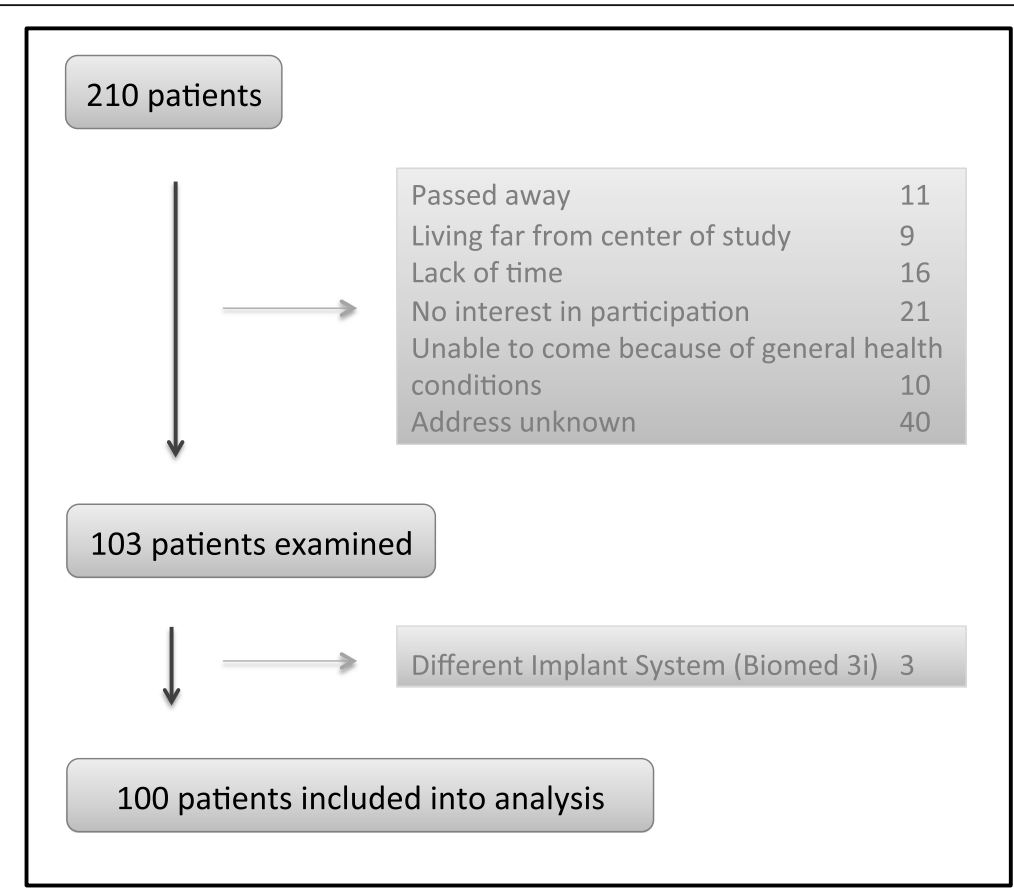

Fig. 1 Recruitment of patients included in the study

gingiva with peri-implantitis, mucositis, $\mathrm{BOP}, \mathrm{mPII}$ and mGI.

\section{Results}

\section{Study population data}

210 patients received an implant treatment during 2003 and 2006 and fulfilled the inclusion criteria, 103 of them could be reexamined (responder rate of $49.1 \%$ ). In the analysis 100 patients aged $28-86$ years (mean 63.8 years, SD 10.3 years) were included 10 years (range 9.5-10.7 years, SD 0.31 years) after implant setting. The reason for exclusion is given in Fig. 1.

$59.0 \%$ were female and most of the patients had a high educational level $(64.0 \%$; $26.0 \%$ moderate, $5.0 \%$ low, $7.0 \%$ unknown). At implant placement $25.0 \%$ were smoker, at reexamination still $10.0 \%$ (former smoker $45.0 \%$, never smoker 45.0\%). A correlation between low smokerlyzer levels and by questionnaire-defined non-smokers could be stated $(p<0.001)$. At baseline $27.0 \%$ of all patients had no periodontitis, $54.0 \%$ a chronic and $16.0 \%$ an aggressive periodontitis. Before implant placement all patients with periodontitis were treated non-surgically, $52.0 \%$ afterwards also surgically. $60.0 \%$ were compliant to the SPT. At reexamination $5.0 \%$ showed a recurrence of periodontitis.

\section{Implants}

A total of 242 implants could be included. 212 Xive S Cellplus implants (87.6\%) in 88 patients (88.0\%), 30 Frialit-2-Synchro implants in 12, respectively. Number of implants per patient is given in Table 1. Time of implant placement, form of augmentation, healing as well as length and diameter of implants is presented in Table 2. After implant placement $8.7 \%$ of all implants needed peri-implant therapy $(5.0 \%$ non-surgical, $3.7 \%$ surgical). At re-examination data regarding bone loss, PPD, width of keratinized gingiva, $\mathrm{mPII}$, mGI and BOP were collected and are given in Table 2 .

\section{Biological complications Survival}

On patient-level survival rate of implants was $94.0 \%$ (XiVE: 97.7\%; Frialit-2-Synchro: 66.7\%). Six patients lost at least one implant (five patients one implant, one patient four implants), five of them received more than one implant. Therefore, 98 patients are included into data collected at re-examination.

The possible influencing factors for implant loss such as age, sex, smoking at implant placement, periodontal diagnosis at re-examination, compliance, number of implants per patient, implant type and recurrence of periodontits were assessed in a regression analysis. A statistically significant influence could be found for the factors 'implant type' $(p<0.001)$ : Frialit-2-Synchro implants were lost more often than XiVE implants (Table 4a).

On implant-level nine implants were lost (survival rate 96.3\%), seven were Frialit-2-Synchro implants and two XiVE. Most of them (8 implants, 3.3\%) were lost in the healing phase, only one implant $(0.4 \%)$ was lost due to 
Table 1 Distribution of implants per patient

\begin{tabular}{ll}
$\begin{array}{l}\text { Number of } \\
\text { implants per } \\
\text { patient }\end{array}$ & $\begin{array}{l}\text { Amount of patients } \\
n=100\end{array}$ \\
\hline 1 Implant & $35(35.0 \%)$ \\
2 impants & $29(29.0 \%)$ \\
3 implants & $15(15.0 \%)$ \\
4 implants & $11(11.0 \%)$ \\
5 implants & $5(5.0 \%)$ \\
6 implants & $3(3.0 \%)$ \\
8 implants & $1(1.0 \%)$ \\
9 implants & $1(1.0 \%)$ \\
\hline
\end{tabular}

peri-implantitis and was removed 8 years after implant placement. Therefore, data of 233 implants is given in the re-examination data.

There were too few events of implant loss, therefore, a regression analysis on implant-level was not possible.

\section{Success}

Mucositis could be found in $77.6 \%$ of all patients and at $61.4 \%$ of all implants (patients/implants with periimplantitis included). None of the factors seemed to have impact on the incidence of mucositis on patientlevel. As influencing factors on implant-level the regression analysis determined a wider implant diameter $(p=$ $0.0438)$ and a higher PI $(p=0.0253)$ as statistically significant (Table 4a). No statistical significance could be found for the factors width of keratinized gingiva, implant length, augmentation of soft/hard tissue and implant healing.

As defined by Derks et al. (2016), on patient-level a peri-implantitis was detected in $54.1 \%$ of all cases and a moderate/severe form of peri-implantitis in $16.3 \%$. Regression analysis for moderate/severe peri-implantitis detected a higher number of implants as influencing factor $(p=0.0075)$ (Table 3b). On implant-level, a periimplantitis could be seen in $41.2 \%$ of all implants and a moderate/severe peri-implantitis in $10.3 \%$. As on mucositis a wider implant diameter seemed to have a statistically significant influence on the incidence of a moderate/severe peri-implantitis $(p=0.0079)$ (Table $4 \mathrm{~b})$.

\section{Width of keratinized gingiva}

31 implants (13.3\%) presented no keratinized gingiva. The width of keratinized gingiva was correlated with peri-implantitis, mucositis, BOP, $\mathrm{mPII}$ and $\mathrm{mGI}$, but showed only statistical significance with the presence of BOP $(p=0.045, r=0.132)$. For the other factors no significance could be found, although mucositis almost proved to be significant $(p=0.075, r=0.177)$.

\section{Technical complications}

Most implants were supported by single crowns (55.6\%). $25.6 \%$ of implants served as bridge anchor for implantsupported fixed dental prostheses (FDP), $17.5 \%$ as anchor for implant-supported removable prostheses, 1.3\% as bridge anchor for combined tooth-implant-supported FDPs. Most implant-supported crowns were cemented (97.4\%).

Technical complications were found in 47 implants (19.4\%). Abutment/screw loosening occurred in 13 cases and was the most common complication (5.3\%) (Table 5). No implant fracture took place.

\section{Discussion}

Long-term data over 10 years regarding survival and success rates of XiVE S and Frialit-2 Synchro implants are rare. Therefore, the aim of this retrospective study was to assess survival and success rates of these implant systems over a follow-up period of 10 years. For XiVE implants similar results as for many other implant systems could be found, the survival rates for Frialit-2 Synchro implants was noticeably lower.

\section{Biological complications}

The observed survival rate over 10 years of $94.0 \%$ (97.7\% for XiVE-implants) on patient-level presents comparable data to another long-term study by Degidi et al. (2016) of $93.0 \%$. Similar survival rates can be found for other implant systems over the same follow-up period [3, 4, 27]. Most implants ( 8 of 9) were lost in the early healing phase prior the implant-supported restoration was connected (5.0\% of patients, $3.3 \%$ of implants), just one in the late phase due to peri-implantitis $(1.0 \%$ of patients, $0.4 \%$ of implants). Also, mostly Frialit-2-Synchro implants were lost. In a large study on early and late implant loss Derks et al. (2015) detected comparable rates of early loss in $4.4 \%$ of patients (1.4\% of implants), but a higher late implant loss in $4.2 \%$ of patients $(1.4 \%$ of implants) 9 years after implant placement. Overall, implant survival rates were in accordance with the long-term data over a follow-up period of 10 years published so far.

In our analysis 'implant type' (Frialit-2-Synchro) was the sole statistically significant influencing factor for implant loss as described by Derks et al. (2015), who detected 'implant brand' as an influencing factor. All other potential influencing factors such as smoking or history of periodontitis had no impact, as supported by several other studies $[2,4,5,16]$. This might be due to the low number of lost implants, wherefore detection of influencing factors on implant-level was not possible. Another reason could be that all periodontally compromised patients had received a periodontal treatment of high quality in the private periodontal practice prior to implant 
Table 2 Implant data at baseline (a) and at re-examination (b)

\begin{tabular}{|c|c|c|c|c|c|}
\hline \multicolumn{6}{|l|}{$\mathrm{a}$} \\
\hline & Total & XiVE & Frialit-2 Synchro & Implant lost & Implant in situ \\
\hline Baseline data & $n=242$ & $n=212$ & $n=30$ & $n=9$ & $n=233$ \\
\hline \multicolumn{6}{|l|}{ Implanttyp } \\
\hline XIVE S Cellplus & $212(87.6 \%)$ & & & $2(0.9 \%)$ & 210 (99.1\%) \\
\hline Frialit-2-Synchro & $30(12.4 \%)$ & & & 7 (23.3\%) & $23(76.7 \%)$ \\
\hline \multicolumn{6}{|l|}{ Implant diametre } \\
\hline $3 \mathrm{~mm}$ & $3(1.3 \%)$ & $3(100 \%)$ & $0(0 \%)$ & $0(0 \%)$ & $3(100 \%)$ \\
\hline $3.4 \mathrm{~mm}$ & $28(11.6 \%)$ & 24 (85.7\%) & $4(14.3 \%)$ & $4(14.3 \%)$ & 24 (85.7\%) \\
\hline $3.8 \mathrm{~mm}$ & $111(45.9 \%)$ & $94(84.7 \%)$ & $17(15.3 \%)$ & $2(1.8 \%)$ & 109 (98.2\%) \\
\hline $4.5 \mathrm{~mm}$ & $88(36.4 \%)$ & 80 (90.9\%) & $8(9.1 \%)$ & $2(2.3 \%)$ & $86(97.7 \%)$ \\
\hline $5.5 \mathrm{~mm}$ & $12(5.0 \%)$ & 11 (91.7\%) & $1(8.3 \%)$ & $1(8.3 \%)$ & $11(91.7 \%)$ \\
\hline \multicolumn{6}{|l|}{ Implant lenght } \\
\hline $8 \mathrm{~mm}$ & $2(0.8 \%)$ & $2(100 \%)$ & $0(0 \%)$ & $0(0 \%)$ & $2(100 \%)$ \\
\hline $9.5 \mathrm{~mm}$ & $10(4.1 \%)$ & $10(100 \%)$ & $0(0 \%)$ & $1(10.0 \%)$ & $9(90.0 \%)$ \\
\hline $10 \mathrm{~mm}$ & $6(2.5 \%)$ & $0(0 \%)$ & $6(100 \%)$ & $2(33.3 \%)$ & $4(66.7 \%)$ \\
\hline $11 \mathrm{~mm}$ & $40(16.5 \%)$ & $39(97.5 \%)$ & $1(2.5 \%)$ & $0(0 \%)$ & $40(100 \%)$ \\
\hline $13 \mathrm{~mm}$ & $138(57.0 \%)$ & $122(88.4 \%)$ & $16(11.6 \%)$ & $1(0.7 \%)$ & $137(99.3 \%)$ \\
\hline $15 \mathrm{~mm}$ & $46(19.0 \%)$ & 39 (84.8\%) & $7(15.2 \%)$ & $5(10.9 \%)$ & $41(89.1 \%)$ \\
\hline \multicolumn{6}{|l|}{ Implant position (Jaw) } \\
\hline Maxilla & $136(56.2 \%)$ & $121(89.0 \%)$ & 15 (11.0\%) & $1(0.7 \%)$ & 135 (99.3\%) \\
\hline Mandible & $106(43.8 \%)$ & $91(85.9 \%)$ & $15(14.1 \%)$ & $8(7.5 \%)$ & $98(92.5 \%)$ \\
\hline \multicolumn{6}{|l|}{ Implant Position } \\
\hline Anterior & $56(23.1 \%)$ & $42(75.0 \%)$ & $14(25.0 \%)$ & $6(10.7 \%)$ & $50(89.3 \%)$ \\
\hline Posterior & $186(76.9 \%)$ & $170(91.4 \%)$ & $16(8.6 \%)$ & $3(1.6 \%)$ & $183(98.4 \%)$ \\
\hline \multicolumn{6}{|l|}{ Time of Implant placement } \\
\hline time of tooth extraction not known & $21(8.7 \%)$ & 17 (81.0\%) & $4(19.0 \%)$ & $0(0 \%)$ & $21(100 \%)$ \\
\hline immediate implant & $23(9.5 \%)$ & $18(78.3 \%)$ & $5(21.7 \%)$ & $4(17.4 \%)$ & $19(82.6 \%)$ \\
\hline delayed immediate implant & $1(0.4 \%)$ & $1(100 \%)$ & $0(0 \%)$ & $0(0 \%)$ & $1(100 \%)$ \\
\hline 6-12-weeks afer extraction & $18(7.4 \%)$ & $15(83.3 \%)$ & $3(16.7 \%)$ & $2(11.1 \%)$ & $16(88.9 \%)$ \\
\hline$>12$ weeks to $<6$ months & $22(9.1 \%)$ & 19 (86.4\%) & $3(13.6 \%)$ & $0(0 \%)$ & $22(100 \%)$ \\
\hline$\geq 6$ Monate & $157(64.9 \%)$ & $142(90.5 \%)$ & $15(9.5 \%)$ & $3(1.9 \%)$ & $154(98.1 \%)$ \\
\hline \multicolumn{6}{|l|}{ Augmentation } \\
\hline none & $51(21.1 \%)$ & $45(88.2 \%)$ & $6(11.8 \%)$ & $1(2.0 \%)$ & $50(98.0 \%)$ \\
\hline internal sinus lift & $9(3.7 \%)$ & $9(100 \%)$ & $0(0 \%)$ & $0(0 \%)$ & $9(100 \%)$ \\
\hline external sinus lift & $54(22.4 \%)$ & $50(92.6 \%)$ & $4(7.4 \%)$ & $0(0 \%)$ & $54(100 \%)$ \\
\hline bone substitute/membran & $111(45.9 \%)$ & $97(87.4 \%)$ & $14(12.6 \%)$ & $4(3.6 \%)$ & $107(96.4 \%)$ \\
\hline block augmentation & $9(3.7 \%)$ & $8(88.9 \%)$ & $1(11.1 \%)$ & $0(0 \%)$ & $9(100 \%)$ \\
\hline soft tissue & $3(1.3 \%)$ & $2(66.7 \%)$ & $1(33.3 \%)$ & $0(0 \%)$ & $3(100 \%)$ \\
\hline distraction osteogeneses & $5(2.1 \%)$ & $1(20.0 \%)$ & $4(80.0 \%)$ & $4(80.0 \%)$ & $1(20.0 \%)$ \\
\hline \multicolumn{6}{|l|}{ Implant healing $(n=234)$} \\
\hline submerged & $176(75.2 \%)$ & $153(86.9 \%)$ & $23(13.1 \%)$ & $1(0.6 \%)$ & $175(99.4 \%)$ \\
\hline non-submerged & $58(24.8 \%)$ & $57(98.3 \%)$ & $1(1.7 \%)$ & $8(13.8 \%)$ & $50(86.2 \%)$ \\
\hline \multicolumn{6}{|l|}{ Connection implant/suprastructure } \\
\hline cemented & $227(93.8 \%)$ & $210(92.5 \%)$ & $17(7.5 \%)$ & $0(0 \%)$ & $227(100 \%)$ \\
\hline screwed & $6(2.5 \%)$ & $0(0 \%)$ & $6(100 \%)$ & $1(16.7 \%)$ & $5(93.3 \%)$ \\
\hline \multicolumn{6}{|l|}{$b$} \\
\hline Reexamination data & Total $n=233$ & & & & \\
\hline PPD (mean per implant) & $3.16 \mathrm{~mm} \pm 1.0$ & & & & \\
\hline
\end{tabular}


Table 2 Implant data at baseline (a) and at re-examination (b) (Continued)

\begin{tabular}{|c|c|}
\hline Bone loss (maximum per implant) & $0.78 \mathrm{~mm} \pm 1.41$ (range $0.00-6.10 \mathrm{~mm})$ \\
\hline$<1 \mathrm{~mm}$ & $63.3 \%$ of all implants \\
\hline $1 \mathrm{~mm}-<2 \mathrm{~mm}$ & $16.5 \%$ \\
\hline $2 \mathrm{~mm}-<3 \mathrm{~mm}$ & $9.4 \%$ \\
\hline $3 \mathrm{~mm}-<4 \mathrm{~mm}$ & $4.7 \%$ \\
\hline$\geq 4 \mathrm{~mm}$ & $6.1 \%$ \\
\hline \multicolumn{2}{|c|}{ BOP (at least one positive site per implant) } \\
\hline positive & $202(86.7 \%)$ \\
\hline negative & $31(13.3 \%)$ \\
\hline \multicolumn{2}{|l|}{ Width of keratinized gingiva } \\
\hline $0 \mathrm{~mm}$ & $31(13.3 \%)$ \\
\hline $0.5 \mathrm{~mm}$ & $1(0.4 \%)$ \\
\hline $1.0 \mathrm{~mm}$ & $32(13.7 \%)$ \\
\hline $1.5 \mathrm{~mm}$ & $1(0.4 \%)$ \\
\hline $2.0 \mathrm{~mm}$ & $70(30.0 \%)$ \\
\hline $3.0 \mathrm{~mm}$ & $48(20.6 \%)$ \\
\hline $3.5 \mathrm{~mm}$ & $1(0.4 \%)$ \\
\hline $4.0 \mathrm{~mm}$ & $27(11.6 \%)$ \\
\hline $5.0 \mathrm{~mm}$ & $13(5.6 \%)$ \\
\hline $6.0 \mathrm{~mm}$ & $9(3.9 \%)$ \\
\hline \multicolumn{2}{|c|}{ mod. Gl (maximum per implant) according to Mombelli et al. (1987) } \\
\hline 0 & $130(55.8 \%)$ \\
\hline 1 & $62(26.6 \%)$ \\
\hline 2 & $32(13.7 \%)$ \\
\hline 3 & $9(3.9 \%)$ \\
\hline \multicolumn{2}{|l|}{ mod. PI (maximum per implant) } \\
\hline 0 & $54(23.2 \%)$ \\
\hline 1 & $71(30.5 \%)$ \\
\hline 2 & $85(36.5 \%)$ \\
\hline 3 & $23(9.9 \%)$ \\
\hline
\end{tabular}

PPD periodontal pocket depth, mod. GI modified Gingiva Index, mod. PI modified Plaque Index, BOP bleeding onb probing

placement and afterwards showed a high compliance to the supportive implant therapy.

The high implant loss rate of Frialit implants might be biased due to the relatively small number of observed implants and that solely one patient lost 4 of those implants in the early healing phase.

For comparison of success rates the definition of mucositits (BOP/suppuration without bone loss) and peri-implantitis (BOP/suppuration and bone loss $>0.5$ $\mathrm{mm}$; moderate/severe peri-implantitis: $\mathrm{BOP} /$ suppuration and bone loss $>2.0 \mathrm{~mm}$, respectively) were chosen from a large study from Sweden [15]. Interestingly, our incidences for moderate/severe peri-implantitis $(16.3 \%$ of patients, $10.3 \%$ of implants) were quite in accordance with the data published by Derks et al. (2016) for moderate/severe peri-implantitis (14.5\% of patients, $8.0 \%$ of implants). Also, our results are reflected in the data published by Mombelli et al. (2012), which provided an incidence of peri-implantitis of $20 \%$ on patient-level and $10 \%$ of implant-level as well as by the one by RoosJansaker et al. (2006) of 16\%. The number of implants per patient could be established as an influencing factor for moderate/severe peri-implantitis, which Derks et al. (2016) also found in their study. Furthermore, on implant-level a wider implant diameter was detected as influencing factor for peri-implantitis. All other risk factors proposed in many other studies such as smoking, history of periodontitis, plaque accumulation or compliance to recall $[4,15,16,18,27]$ reached no statistically significant influence in our analysis. Also, the often discussed factor 'width of keratinized gingiva' could not been detected as influencing factor for peri-implantitis in regression analyses, even if there was a slight correlation between width of keratinized gingiva and higher mod. PI at the implant. Also, higher mod. PI as well as a wider implant diameter was associated with peri-implant 
Table 3 Regression analyses regarding patient-related factors

\begin{tabular}{|c|c|c|c|c|}
\hline & Estimate & SE & $t$ & $P$ \\
\hline \multicolumn{5}{|c|}{ a. Regression analysis: implant loss in relation to patient-related factors } \\
\hline (Intercept) & -0.2056 & 0.1823 & -1.128 & 0.262 \\
\hline Age (1 year) & 0.0025 & 0.0028 & 0.922 & 0.359 \\
\hline Sex (female) & 0.0482 & 0.0577 & 0.835 & 0.406 \\
\hline Smoking at implant placement & -0.0513 & 0.0651 & -0.789 & 0.432 \\
\hline Periodontal diagnosis at baseline & 0.0077 & 0.0183 & 0.418 & 0.677 \\
\hline Compliance & 0.0641 & 0.0587 & 1.093 & 0.277 \\
\hline Counts of implants in each patient & 0.0021 & 0.0179 & 0.118 & 0.907 \\
\hline Implant type & 0.3755 & 0.0879 & 4.274 & $<0.001$ \\
\hline Recurrence of periodontitis at reexamination & -0.0671 & 0.1305 & -0.514 & 0.609 \\
\hline \multicolumn{5}{|c|}{ b. Regression analysis: incidence of moderate/severe peri-implantitis in relation to patient-related factors } \\
\hline (Intercept) & -0.1003 & 0.2518 & -0.398 & 0.6913 \\
\hline Age (1 year) & 0.0015 & 0.0038 & 0.395 & 0.6939 \\
\hline Sex (female) & -0.0495 & 0.0798 & -0.621 & 0.5363 \\
\hline Smoking at implant placement & 0.0932 & 0.0905 & 1.029 & 0.3061 \\
\hline Periodontal diagnosis at baseline & 0.0048 & 0.0250 & 0.190 & 0.8497 \\
\hline Compliance & 0.0370 & 0.0803 & 0.461 & 0.6459 \\
\hline Counts of implants in each patient & 0.0673 & 0.0246 & 2.734 & 0.0075 \\
\hline Implant type & -0.1098 & 0.1252 & -0.877 & 0.3829 \\
\hline Recurrence of periodontitis at reexamination & -0.1087 & 0.1777 & -0.612 & 0.5422 \\
\hline
\end{tabular}

Dependent variable: implant loss after 10 years; $n=100$

Dependent variable: moderate/severe peri-implantitis after 10 years; $n=100$

Table 4 Regression analyses regarding implant-related factors

\begin{tabular}{|c|c|c|c|c|}
\hline & Estimate & SE & $t$ & $P$ \\
\hline \multicolumn{5}{|c|}{ a. Regression analysis: incidence of mucositis in relation to implant-related factors } \\
\hline (Intercept) & -6.3125 & 3.0371 & -2.0785 & 0.0377 \\
\hline Width of keratinized gingiva & 0.2260 & 0.1493 & 1.513 & 0.1302 \\
\hline Implant length & 0.0923 & 0.1580 & 0.5846 & 0.5588 \\
\hline Implant diametre & 0.9410 & 0.4668 & 2.0160 & 0.0438 \\
\hline Augmentation of hard/soft tissue & 0.1830 & 0.1917 & 0.9549 & 0.3396 \\
\hline Implant healing (submerged) & 0.6991 & 0.6353 & 1.1003 & 0.2712 \\
\hline Implant type & -0.2532 & 0.8666 & -0.2922 & 0.7701 \\
\hline Plaque Index & 0.6068 & 0.2713 & 2.2367 & 0.0253 \\
\hline \multicolumn{5}{|c|}{ b. Regression analysis: incidence of moderate/severe peri-implantitis in relation to implant-related factors } \\
\hline (Intercept) & 4.3652 & 15.3687 & 0.2840 & 0.7764 \\
\hline Width of keratinized gingiva & -0.8289 & 0.4598 & -1.8028 & 0.0714 \\
\hline Implant length & 0.6268 & 0.9761 & 0.6422 & 0.5208 \\
\hline Implant diametre & -4.9021 & 1.8460 & -2.6555 & 0.0079 \\
\hline Augmentation of hard/soft tissue & -0.2617 & 1.3961 & -0.1875 & 0.8513 \\
\hline Implant healing (submerged) & -1.1041 & 6.0597 & -0.1822 & 0.8554 \\
\hline Implant type & -16.0250 & 10.8131 & -1.4820 & 0.1383 \\
\hline Plaque Index & 1.0647 & 0.8470 & 1.2570 & 0.2087 \\
\hline
\end{tabular}

Dependent variable: mucositis after 10 years; $n=233$ 
Table 5 Technical complications

\begin{tabular}{ll}
\hline & $\begin{array}{l}\text { Implants } \\
n=242\end{array}$ \\
\hline $\begin{array}{l}\text { No complication } \\
\text { Complications (more than one per implant possible) }\end{array}$ & $47(19.4 \%)$ \\
$\begin{array}{l}\text { a) Major complications } \\
\text { Implant fracture }\end{array}$ & $0(0 \%)$ \\
Loss of supraconstruction & $4(1.7 \%)$ \\
b) Medium complications & \\
Abutmend fracture & $1(0.4 \%)$ \\
Veneer or framwork fracture & $10(4.0 \%)$ \\
Phonetic complications & $0(0 \%)$ \\
c) Minor complications & \\
Abutmend/screw loosening & $13(5.3 \%)$ \\
De-bonding & $0(0 \%)$ \\
Loss of retention & $3(1.2 \%)$ \\
Minor chipping & $10(4.0 \%)$ \\
\hline
\end{tabular}

mucositis. That plaque accumulation results in periimplant mucositis was often stated by different authors $[17,27-29]$ and is underlined by our data.

\section{Technical complications}

There still seems to exist a substantial lack of wellperformed longitudinal reports on implant-supported restoration over an observation period of ten or more years [30]. In our studies, technical complications occurred in about $20 \%$ of all implants, comparable to the 16-years results by Simonis et al. (2010) with $31.1 \%$. The most common complication over this 10 years follow-up was abutment/screw loosening, which occurred in $5.3 \%$ of all implants. Chipping could be observed in $4.0 \%$ of all implant-supported restorations and is comparable with chipping of the veneering material of fixed dental prosthesis (4.1\%) in an actual review assessed over 5and 10-years [31].

\section{Limitations}

This analysis has some limitations (retrospective design, limited number of patients and implants with few events regarding implant loss) and could potentially be biased because of a relatively homogenous clientele of mostly highly educated patients, a high quality standard of den$\mathrm{tal} /$ periodontal care in a specialized periodontal practice and the form of recruitment (few implants of the brand Frialit-2-Synchro compared to XiVE implants). On the other hand, the enrolled patients showed a high heterogeneity regarding age (between 28 and 86 years), smoking status and history of periodontitis. Also, a wide heterogeneity regarding form and extent of augmentation, point of time of implantation after extraction or variations in type of implant loading could have influenced the results. Likewise, the inconsistent distribution of insertion of the two different implant types (XiVE or Frialit-2 Synchro) could have biased the data. Also, the responder rate of about $50 \%$ could lead to a selection bias (e.g. patients were not willing to participate possibly due to dissatisfaction/problems with their implants).

\section{Conclusions}

In this retrospective long-term study over 10 years on XiVE S Cellplus/Frialit-2-Synchro implants survival and success rates are assessed. This data show high survival rates of implants and comparable incidences of periimplant mucositits and peri-implantitis for XiVE implants compared to other implant systems; for the system Frialit-2 Synchro the result were worse. However, the source of bias of this study has to be kept in mind due to variable aspects. Major technical complications occurred rarely, some minor complications could be detected.

\section{Abbreviations}

APT: Active periodontal therapy; BOP: Bleeding on probing; PPD: Periodontal pocket depth; CAL-V: Vertical attachment level; SUP: Suppuration; mGl: Modified gingival index; mPII: Modified plaque index; SD: Standard deviation; FDP: Fixed dental prosthesis

\section{Acknowledgements}

Not applicable.

\section{Authors' contributions}

GK inserted all implants. AB examined all included patients retrospectively. ST entered all data on the basis of the file search. DS analyzed and interpreted the data (statistician). AB and GK were major contributors in writing the manuscript. All authors read and approved the final manuscript.

\section{Funding}

The work was supported by Fa. Dentsply Sirona Implants (Mannheim, Germany) (grant number DF-05-13-1-321-1-2). It was self-funded by the authors and their institutions in its major parts.

\section{Availability of data and materials}

The datasets used and analysed during the current study are available from the corresponding author on reasonable request.

\section{Ethics approval and consent to participate}

The study was performed in accordance with the Declaration of Helsinki 1975, as revised in 2008, and was approved by the Institutional Review Board for Human Studies of the Medical Faculty of Heidelberg University (Application\# S-210/2013). All patients were informed about possible risks and benefits as well as the procedures of the study and all gave written informed consent

\section{Consent for publication}

Not applicable.

\section{Competing interests}

Author A. Bäumer declares that she has received research grants from Company Dentsply Sirona Implant, Hain Life Sciene and speaker honorarium from the following Companies: American Dental Systems, Dentsply Sirona Implant and Tecnoss. Author G. Körner has received speaker honorarium from the following Companies: American Dental Systems, Geistlich, Dentsply Sirona Implant, Tecnoss, Nobel Biocare, Quintessence, Camlog, 3i, Gebrüder Martin, BEGO. The authors D. Saure and S. Toekan declare that they have no conflict of interest. 


\section{Author details}

'Section of Periodontology, Department of Conservative Dentistry, Clinic for Oral, Dental and Maxillofacial Diseases, University Hospital Heidelberg, Im Neuenheimer Feld 400, 69120 Heidelberg, Germany. ${ }^{2}$ Private Practice, Niedernstrasse 16, 33602 Bielefeld, Germany. ${ }^{3}$ Private Practice, Dortmund, Germany. ${ }^{4}$ Institute of Medical Biometry and Informatics, University of Heidelberg, 69120 Heidelberg, Germany.

\section{Received: 15 May 2019 Accepted: 5 March 2020}

Published online: 30 March 2020

\section{References}

1. Simonis P, Dufour T, Tenenbaum H. Long-term implant survival and success: a 10-16-year follow-up of non-submerged dental implants. Clin Oral Implants Res. 2010;21(7):772-7. https://doi.org/10.1111/j.1600-0501.2010. 01912.x

2. Derks J, Tomasi C. Peri-implant health and disease. A systematic review of current epidemiology Journal of clinical periodontology. 2015;42(Suppl 16): S158-71. https://doi.org/10.1111/jcpe.12334.

3. Mertens C, Steveling HG, Stucke K, Pretzl B, Meyer-Baumer A. Fixed implantretained rehabilitation of the edentulous maxilla: 11-year results of a prospective study. Clin Implant Dent Relat Res. 2012;14(6):816-27. https:// doi.org/10.1111/j.1708-8208.2011.00434.x.

4. Roccuzzo M, Bonino L, Dalmasso P, Aglietta M. Long-term results of a three arms prospective cohort study on implants in periodontally compromised patients: 10-year data around sandblasted and acid-etched (SLA) surface. Clin Oral Implants Res. 2014;25(10):1105-12. https://doi.org/10.1111/clr.12227.

5. Degidi M, Nardi D, Piattelli A. 10-year prospective cohort follow-up of immediately restored XiVE implants. Clin Oral Implants Res. 2016;27(6):694700. https://doi.org/10.1111/clr.12642.

6. Gjelvold B, Chrcanovic BR, Bagewitz IC, Kisch J, Albrektsson T, Wennerberg A. Esthetic and patient-centered outcomes of single implants: a retrospective study. Int J Oral Maxillofac Implants. 2017. https://doi.org/10. 11607/jomi.5495.

7. De Wijs FL, Van Dongen RC, De Lange GL, De Putter C. Front tooth replacement with Tubingen (Frialit) implants. J Oral Rehabil. 1994;21(1):1126. https://doi.org/10.1111/j.1365-2842.1994.tb01120.x.

8. Gomez-Roman G, Launer S. Peri-implant bone changes in immediate and non-immediate root-analog stepped implants-a matched comparative prospective study up to 10 years. Int J Implant Dent. 2016;2(1):15. https:// doi.org/10.1186/s40729-016-0048-0.

9. Derks J, Schaller D, Hakansson J, Wennstrom JL, Tomasi C, Berglundh T. Periimplantitis - onset and pattern of progression. J Clin Periodontol. 2016;43(4): 383-8. https://doi.org/10.1111/jcpe.12535.

10. Mombelli A, Muller N, Cionca N. The epidemiology of peri-implantitis. Clin Oral Implants Res. 2012;23(Suppl 6):67-76. https://doi.org/10.1111/j.16000501.2012.02541.x

11. Jepsen S, Berglundh T, Genco R, Aass AM, Demirel K, Derks J, Figuero E, Giovannoli JL, Goldstein M, Lambert F, Ortiz-Vigon A, Polyzois I, Salvi GE, Schwarz F, Serino G, Tomasi C, Zitzmann NU. Primary prevention of periimplantitis: managing peri-implant mucositis. J Clin Periodontol. 2015; 42(Suppl 16):S152-7. https://doi.org/10.1111/jcpe.12369.

12. Aglietta M, Siciliano VI, Rasperini G, Cafiero C, Lang NP, Salvi GE. A 10-year retrospective analysis of marginal bone-level changes around implants in periodontally healthy and periodontally compromised tobacco smokers. Clin Oral Implants Res. 2011;22(1):47-53. https://doi.org/10.1111/j.1600-0501. 2010.01977.x.

13. Heitz-Mayfield LJ, Huynh-Ba G. History of treated periodontitis and smoking as risks for implant therapy. Int J Oral Maxillofac Implants. 2009;24(Suppl): 39-68.

14. Strietzel FP, Reichart PA, Kale A, Kulkarni M, Wegner B, Kuchler I. Smoking interferes with the prognosis of dental implant treatment: a systematic review and meta-analysis. J Clin Periodontol. 2007;34(6):523-44. https://doi. org/10.1111/j.1600-051X.2007.01083.X.

15. Derks J, Schaller D, Hakansson J, Wennstrom JL, Tomasi C, Berglundh T. Effectiveness of implant therapy analyzed in a Swedish population: prevalence of Peri-implantitis. J Dent Res. 2016;95(1):43-9. https://doi.org/10. 1177/0022034515608832

16. Matarasso S, Rasperini G, lorio Siciliano V, Salvi GE, Lang NP, Aglietta M. A 10-year retrospective analysis of radiographic bone-level changes of implants supporting single-unit crowns in periodontally compromised vs. periodontally healthy patients. Clin Oral Implants Res. 2010;21(9):898-903. https://doi.org/10.1111/j.1600-0501.2010.01945.x.

17. Ferreira SD, Silva GL, Cortelli JR, Costa JE, Costa FO. Prevalence and risk variables for peri-implant disease in Brazilian subjects. J Clin Periodontol. 2006;33(12):929-35. https://doi.org/10.1111/j.1600-051X.2006.01001.x.

18. Costa FO, Takenaka-Martinez S, Cota LO, Ferreira SD, Silva GL, Costa JE. Periimplant disease in subjects with and without preventive maintenance: a 5year follow-up. J Clin Periodontol. 2012;39(2):173-81. https://doi.org/10. 1111/j.1600-051X.2011.01819.x.

19. Wilson TG Jr. The positive relationship between excess cement and periimplant disease: a prospective clinical endoscopic study. J Periodontol. 2009;80(9):1388-92. https://doi.org/10.1902/jop.2009.090115.

20. Eickholz P, Kaltschmitt J, Berbig J, Reitmeir P, Pretzl B. Tooth loss after active periodontal therapy. 1: patient-related factors for risk, prognosis, and quality of outcome. J Clin Periodontol. 2008:35(2):165-74. https://doi.org/10.1111/j. 1600-051X.2007.01184.x.

21. Baumer A, El Sayed N, Kim TS, Reitmeir P, Eickholz P, Pretzl B. Patient-related risk factors for tooth loss in aggressive periodontitis after active periodontal therapy. J Clin Periodontol. 2011;38(4):347-54. https://doi.org/10.1111/j.1600051X.2011.01698.x

22. Lang NP, Tonetti MS. Periodontal risk assessment (PRA) for patients in supportive periodontal therapy (SPT). Oral Health Prev Dent. 2003;1(1):7-16.

23. Hamp SE, Nyman S, Lindhe J. Periodontal treatment of multirooted teeth. Results after 5 years. J Clin Periodontol. 1975;2(3):126-35.

24. Mombelli A, van Oosten MA, Schurch E Jr, Land NP. The microbiota associated with successful or failing osseointegrated titanium implants. Oral Microbiol Immunol. 1987;2(4):145-51.

25. Armitage GC. Development of a classification system for periodontal diseases and conditions. Ann Periodontol. 1999;4(1):1-6. https://doi.org/10. 1902/annals.1999.4.1.1.

26. Sanz M, Chapple IL. Clinical research on peri-implant diseases: consensus report of working group 4. J Clin Periodontol. 2012;39(Suppl 12):202-6. https://doi.org/10.1111/j.1600-051X.2011.01837.x

27. Roos-Jansaker AM, Lindahl C, Renvert H, Renvert S. Nine- to fourteen-year follow-up of implant treatment. Part I: implant loss and associations to various factors. J Clin Periodontol. 2006;33(4):283-9. https://doi.org/10.1111/j. 1600-051X.2006.00907.x.

28. Renvert S, Polyzois I. Risk indicators for peri-implant mucositis: a systematic literature review. J Clin Periodontol. 2015;42(Suppl 16):S172-86. https://doi. org/10.1111/jcpe.12346.

29. Renvert S. Polyzois IN (2015) clinical approaches to treat peri-implant mucositis and peri-implantitis. Periodontology. 2000;68(1):369-404. https:// doi.org/10.1111/prd.12069.

30. Lang NP, Zitzmann NU. Clinical research in implant dentistry: evaluation of implant-supported restorations, aesthetic and patient-reported outcomes. J Clin Periodontol. 2012;39(Suppl 12):133-8. https://doi.org/10.1111/j.1600051X.2011.01842.x

31. Thoma DS, Sailer I, loannidis A, Zwahlen M, Makarov N, Pjetursson BE. A systematic review of the survival and complication rates of resin-bonded fixed dental prostheses after a mean observation period of at least 5 years. Clin Oral Implants Res. 2017. https://doi.org/10.1111/clr.13007.

\section{Publisher's Note}

Springer Nature remains neutral with regard to jurisdictional claims in published maps and institutional affiliations.

Ready to submit your research? Choose BMC and benefit from

- fast, convenient online submission

- thorough peer review by experienced researchers in your field

- rapid publication on acceptance

- support for research data, including large and complex data types

- gold Open Access which fosters wider collaboration and increased citations

- maximum visibility for your research: over $100 \mathrm{M}$ website views per year

At BMC, research is always in progress.

Learn more biomedcentral.com/submission 